\title{
STEREOTACTIC NEURONAVIGATION-ASSISTED EVACUATION OF INTRACRANIAL ABSCESS LOCALIZED IN THE THALAMUS. A CASE REPORT
}

\author{
Elena Harizanova ${ }^{1}$, Yavor Enchev², Bogomil Iliev², Toni Kondev², Martin Moynov², \\ Stephanie Mariyanova ${ }^{2}$ \\ ${ }^{1}$ Student, Faculty of Medicine, Medical University of Varna \\ ${ }^{2}$ Department of Neurosurgery and ENT diseases, Division of Neurosurgery, \\ Faculty of Medicine, Medical University of Varna
}

\begin{abstract}
INTRODUCTION: A brain abscess is a localized focal area of intracerebral infection that develops into a collection of pus surrounded by a well vascularized capsule. It has a rare incidence of $2 \%$ of all space occupying lesions and the deep-seated thalamus as a location is reported in 1.3 to $6 \%$ of all brain abscesses. The use of stereotactic neuronavigation-guided surgical evacuation is a minimally invasive option for achieving good treatment results.

MATERIALS AND METHODS: A 67-year-old female with constant headache, vertigo, staggering and muscle weakness for the right leg developed memory problems and confusion few days prior to admission in the Department of Neurosurgery. Upon examination, raised intracranial pressure, right-sided spastic hemiparesis, and memory and cognitive disturbance were present. The laboratory results showed leukocytosis, elevated glucose, cholesterol and C-reactive protein levels. A computed tomography (CT) scan showed a circular ring-like lesion localized in the region of the left thalamus that enhanced its peripheral hyperdensity after contrast application. Neuronavigation-assisted surgical evacuation was executed. A biopsy needle was inserted in the left thalamic region and the evacuated sample was sent for pathological and microbiological examinations.

RESULTS: The lesion was verified as an abscess and antibiotic therapy was prescribed for 20 days based upon the isolated bacterium and its sensitivity.

CONCLUSION: An abscess localized in the deep-seated region of the brain is a diagnostic and therapeutic challenge. Frameless neuronavigation-guided surgical procedure is an elegant option for minimally invasive approach that allows evacuation and additional examination for correct diagnosis and effective treatment.
\end{abstract}

Keywords: neurosurgery, nervous system, thalamic abscess, intracranial abscess

Address for correspondence:

Elena Harizanova

Medical University of Varna

55 Marin Drinov St

9002 Varna

Bulgaria

e-mail:elena.d.harizanova@gmail.com

Received: September 23, 2018

Accepted: December 22, 2018 


\section{INTRODUCTION}

A brain abscess is a localized focal area of intracerebral infection (cerebritis) that develops into a collection of pus surrounded by a well vascularized capsule $(1,2)$. In the developing world it has a relatively rare incidence of $2 \%$ of all space occupying lesions. The deep-seated thalamus as location for this inflammatory process is reported in 1.3 to $6 \%$ of all brain abscesses (3). The treatment options for such lesions are somewhat limited and every single case is a therapeutic challenge for the physician. The neuronavigation-guided surgical procedure is an elegant minimally invasive option for achieving good treatment results.

\section{MATERIALS AND METHODS}

A 67-year-old female was complaining of constant headache, vertigo, staggering, and muscle weakness in the right leg for 2 weeks before coming to the Department of Neurosurgery. Few days prior to admission memory problems and confusion started to manifest.

Upon examination the patient had symptoms of increased intracranial pressure, right-sided spastic hemiparesis, and memory and cognitive disturbance. The Glasgow Coma Scale (GCS) was 15.

The laboratory results showed slight leukocytosis - 11.56x109 g/L (normal range 4.0-10.0x109 $\mathrm{g} / \mathrm{L}$ ), an elevated glucose level - $11.1 \mathrm{mmol} / \mathrm{L}$ (normal range 4.1- $5.9 \mathrm{mmol} / \mathrm{L}$ ), elevated cholesterol level - $5.92 \mathrm{mmol} / \mathrm{L}$ (normal range $2.70-5.20 \mathrm{mmol} / \mathrm{L}$ ), and abnormal level of the inflammatory marker Creactive protein $(\mathrm{CRP})-16.53 \mathrm{mg} / \mathrm{L}$ (normal range 0-5 mg/L).

A computed tomography (CT) scan showed a $21 \mathrm{~mm}$ circular ring-like lesion localized in the region of the basal ganglia, on the left. There was no sign of edema. After application of the contrast material, the peripheral $2 \mathrm{~mm}$ hyperdense ring of the lesion enhanced its hyperdensity and the center remained hypodense with no change compared to the uncontrasted image. On the CT scan, slight compression of the third ventricle and dislocation on the middle axis were also visible (Fig. 1).

The medical history of the patient, the physical examination, the laboratory results and the imaging pointed to a differential diagnosis of a primary tu-
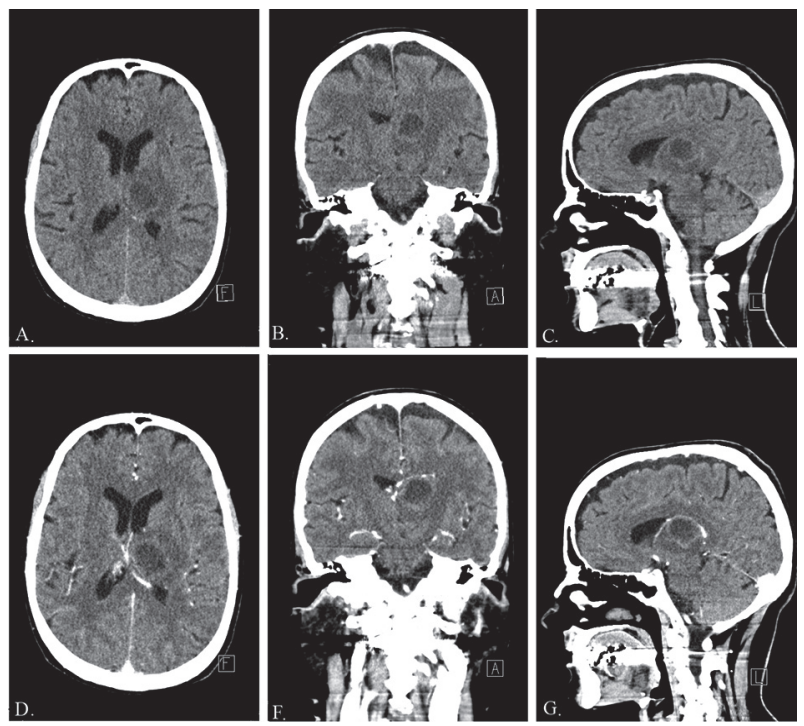

Fig. 1. Preoperative CT scan

mor, a secondary tumor (metastasis), and an abscess occupying the deep-seated part of the cerebrum - the left thalamus. After discussion on all aspects of the

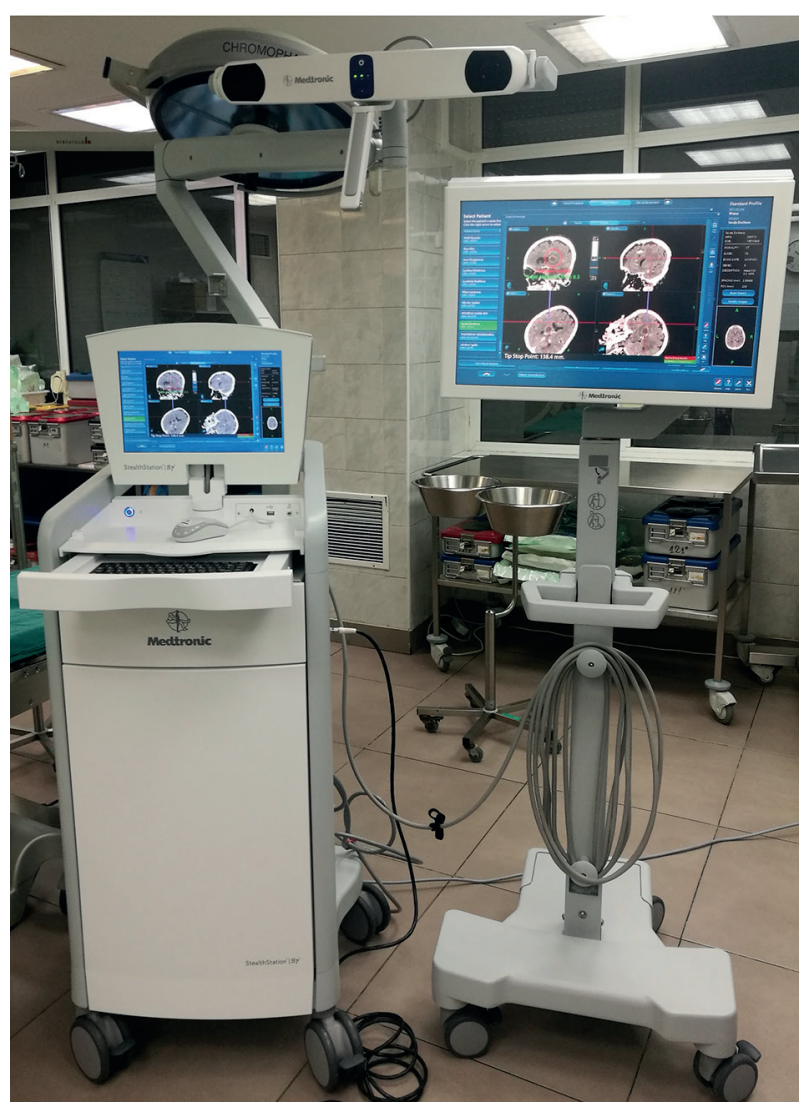

Fig. 2. Medtronic StealthStation S7 surgical navigation system 
case and the possible treatment options, a decision for surgical intervention was made. Given the specific localization of the lesion at the base of the cerebrum the operating team decided to use Medtronic StealthStation S7 surgical navigation system available in the department (Fig. 2).

The CT sequence data was loaded onto the navigation system software. Then the patient was positioned on the back with head placed on a Mayfield 3-pin holder with rotation to the right. Registration of imaging to physical space was carried out (Fig. 3.).

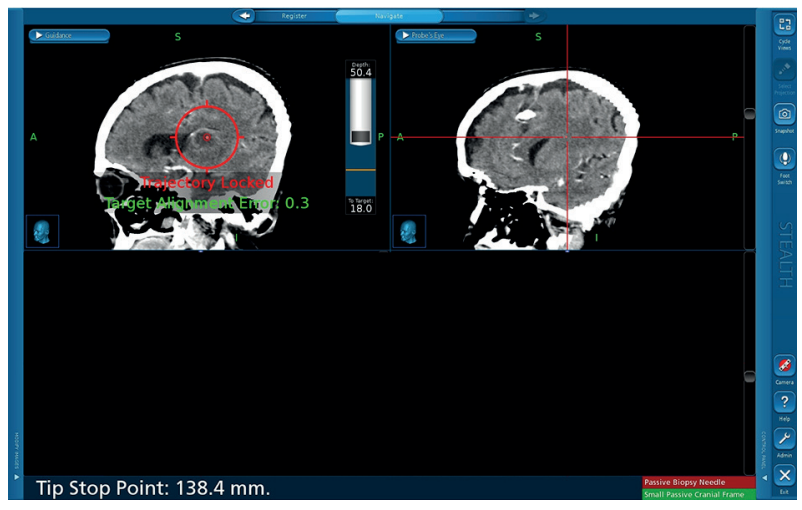

Fig. 3. Neuronavigation trajectory guidance screenshot

An incision in the left frontal region followed. Craniectomy with dural periostal sutures was the next steps. After that, in a section of the dura matter, an image-guided biopsy needle was inserted through the frontal brain region into the left thalamus (Fig. 4).

Aspiration followed. The overall duration of the operation was 1 hour.

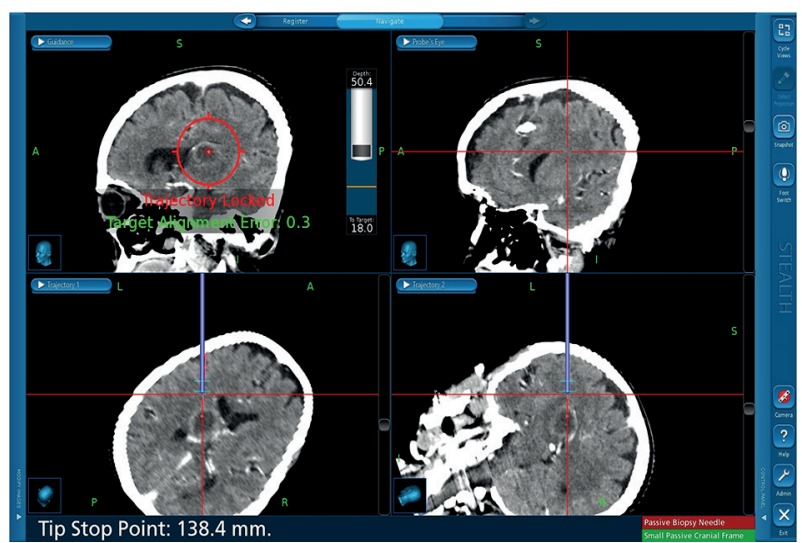

Fig. 4. Neuronavigation-assisted insertion of biopsy needle into the lesion

\section{RESULTS}

By inserting the biopsy needle in the left thalamic region it was possible to evacuate $3 \mathrm{~mL}$ of thick, turbid, brown-red colored liquid. The sample was sent for pathological examination and, based on the macroscopic and microscopic features, the substance was classified as pus and accordingly the lesion was verified to be an abscess. The evacuated sample not only provided the correct diagnosis, but was also used for microbial culture to find the specific bacterium - a coagulase-negative Staphylococcus - and its antibiotic sensitivity (antibiogram).

The successful drainage of the abscess (Fig. 5.) and the appropriate antibiotic therapy prescribed for 20 days based upon the antibiogram results proved to be an effective treatment for our patient who was discharged 6 days after the surgical intervention with improvement of the neurological symptoms.
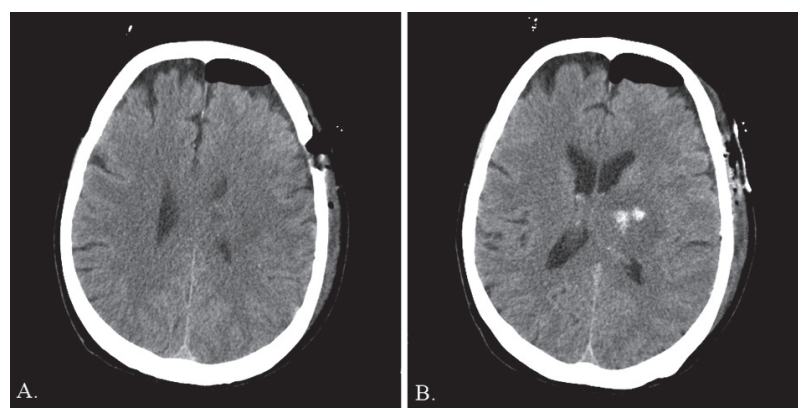

Fig. 5. Postoperative CT scan

\section{DISCUSSION}

Keeping this case in consideration, a couple of aspects need to be taken into consideration and discussed.

One of them is choosing the appropriate treatment method - a conservative one with antibiotic therapy only or combination of surgical intervention and antibiotics. On one hand an abscess localized in the brain has a unique protector - the bloodbrain barrier (BBB) and on the other, the lesion itself has a fibrous capsule with specific permeability $(4,5)$. In vivo studies have demonstrated that an appropriately chosen antibiotic in an optimal dosage regimen can achieve substantial concentrations in the abscess. However, despite the high concentration within the cavity, additional factors, like the level of $\mathrm{pH}$, protein binding and degradation by the bacterial en- 
zymes can lower the efficacy of the antibiotic therapy (6). A number of reports stated that monotherapy or a combination of antibiotics alone leads to a successful treatment of patients with brain abscesses with no significant difference in morbidity or mortality rates compared to patents that have undergone a surgical procedure $(7,8,9,10)$. However, an important note is that the surgical procedure has both diagnostic and therapeutic value. Excision of the abscess or aspiration with biopsy needle of the pus allows identification of the causative bacterium and its antibiotic sensitivity in up to $85 \%$ of the cases. Thus a proper therapy can be chosen to lower the chance of antibiotic resistance and also reduce the size of the lesion using significantly shorter courses of antibiotic treatment are possible $(9,10,11,12)$. Frame-based stereotactic or frameless navigation-assisted surgical aspiration and drainage also have the advantage of intracavitary instillation of antibiotics, which is shown to reduce the length of systemic therapy, thus avoiding the side effects of the drugs, shortening the hospital stay and having economic importance by reducing the cost (13). The combination of surgical and antibiotic treatment gives the best therapeutic results and only selected cases can be treated conservatively (14). Excision or aspiration of the abscess is recommended in the cases where the diameter of the lesion is more than $2.5 \mathrm{~mm}$ or there is mass effect (15).

Another thing to consider is the imaging modalities. CT scan and magnetic resonance imaging (MRI) do not have absolute sensitivity and specificity. In a number of cases, a ring-enhancing lesion on a CT scan suggests a neoplasm and only surgical intervention permits the correct diagnosis of an abscess and its proper treatment. A highly specific and sensitive modality that can differentiate pyogenic brain abscess from necrotic tumor is the diffusion-weighted MRI sequence. However, it is rarely used in the clinical practice $(9,12,16)$.

Deep-seated lesions have an important anatomical proximity with the ventricular system. There is experimental data that suggests a different structure of the capsule formation on the cortical side compared to the ventricular one. As the cortical one is thicker, the brain abscess is prone to spontaneously rupture medially into the ventricle rather than laterally onto the cortical surface $(17,18)$. If this rare complication occurs, a poor outcome for the patients is to be expected with mortality rates ranging from $40 \%$ to $80 \%$. For this reason, in the case of deep-seated abscesses with high risk of spontaneous rupture into the ventricles, the lesion must be aggressively treated as soon as possible by evacuation methods in combination with appropriate intravenous administration of antibiotics (19).

Considering the previous points in this discussion the eternal question to operate or not to operate should be changed to how to operate. Different minimally invasive approaches to the basal ganglia have been reported, including stereotactic aspiration, repeated aspiration, freehand aspiration, stereo-endoscopic aspiration and ultrasound-guided aspiration. Ever since its introduction, frameless stereotactic surgery has been evolving and improving, and today the image-guided target localization is shown to be comparable and at times even superior to the classic frame-based localization $(21,22)$.

\section{CONCLUSION}

An abscess localized in the deep-seated regions of the brain is a diagnostic and therapeutic challenge even to the most experienced medical practitioner. The rarity of cases and thus the experience in the field, the limitations of the antibiotic treatment and the localization perplexity of the surgical approach are among the reasons for the difficult treatment of these lesions. Frameless neuronavigation imageguided surgical procedure is an elegant option for the minimally invasive approach to deep-seated lesions. Consecutive evacuation can be used for additional examination aiding the diagnosis in order to provide the best possible treatment of the patient.

\section{REFERENCES}

1. Baev S, Karkeselyan A. Surgery. Volume 5 Neurosurgery. $1^{\text {st }}$ ed. Znanie; 2000.

2. Mathisen G, Johnson J. Brain abscess. Clin Infect Dis. 1997; 25 (4): 763-79. doi: 10.1086/515541.

3. Lutz TW, Landott H, Wasner M. Diagnosis and management of abscess in the basal ganglia and thalamus: a survey. Acta Neurochir (Wien). 1994;127(1-2):91-8. doi: 10.1007/bf01808554.

4. Cabrera-Maqueda JM, Fuentes Rumí, Valero López G, Baidez Guerrero AE, García Molina E, Díaz Pérez J, et al. Antibiotic diffusion to central nervous system. Rev Esp Quimioter. 2018;31(1):1-12. 
Elena Harizanova, Yavor Enchev, Bogomil Iliev, et al.

5. Barza M, Cuchural G. General principles of antibiotic tissue penetration. J Antimicrob Chemother. 1985; 15 Suppl A:59-75. doi: 10.1093/jac/15. suppl_a.59.

6. Wagner C, Sauermann R, Joukhadar C. Principles of antibiotic penetration into abscess fluid. Pharmacology. 2006; 78(1):1-10. doi: 10.1159/000094668.

7. Sauermann R, Karch R, Langenberger H, Kettenbach J, Mayer-Helm B, Petsch M, et al. Antibiotic abscess penetration: Fosfomycin levels measured in pus and simulated concentration-time profiles. Antimicrob Agents Chemother. 2005; 49(11): 4448-54. doi: 10.1128/AAC.49.11.4448-4454.2005.

8. Tanaka T, Sakamoto H, Kato N, Arai T, Hasegawa Y. Successful treatment of brain stem and thalamic abscesses with high-dose meropenem. Brain Nerve. 2011;63(8):891-6.

9. Tonon E, Scotton PG, Gallucci M, Vaglia A. Brain abscess: clinical aspects of 100 patients. Int J Infect Dis. 2006;10(2):103-9. doi: 10.1016/j. ijid.2005.04.003.

10. Mampalam TJ, Rosenblum ML.

Trends in the management of bacteri-

al brain abscesses: a review of 102 cases over 17 years. Neurosurgery. 1988; 23(4):451-8. doi: 10.1227/00006123-198810000-00008.

11. Sjölin J, Lilja A, Eriksson N, Arneborn P, Cars O. Treatment of brain abscess with cefotaxime and metronidazole: prospective study on 15 consecutive patients. Clin Infect Dis. 1993; 17(5):857-63. doi: 10.1093/clinids/17.5.857.

12. de Lastours V, Fantin B. Pyogenic brain abscesses in adults. Rev Med Interne. 2016; 37(6):412-7. doi: 10.1016/j.revmed.2015.11.010.

13. Yu X, Liu R, Wang Y, Zhao H, Chen J, Zhang J, et al. CONSORT: May stereotactic intracavity administration of antibiotics shorten the course of systemic antibiotic therapy for brain abscesses? Medicine (Baltimore). 2017; 96(21): e6359. doi: 10.1097/ MD.0000000000006359.

14. Carpenter JL. Brain stem abscesses: cure with medical therapy, case report and review. Clin Infect Dis. 1994;18(2):219-26. doi: 10.1093/clinids/18.2.219.

15. Calfee DP, Wispelwey B. Brain abscess. Semin Neurol. 2000; 20(3):353-60. doi: 10.1055/s-2000-9397.

16. Whelan MA, Hilal SK. Computed tomography as a guide in the diagnosis and follow-up of brain abscesses. Radiology. 1980;135(3):663-71. doi: 10.1148/ radiology.135.3.7384453.
17. Britt RH, Enzmann DR. Neuropathological and computerized tomographic findings in experimental brain abscess. J Neurosurg. 1981;55(4):590-603. doi: 10.3171/jns.1981.55.4.0590.

18. Wood JH, Doppman JL, Lightfoote WE, Girton M OA. Role of vascular proliferation on angiographic appearance and encapsulation of experimental traumatic and metastatic brain abscesses. J Neurosurg. 1978;48(2):264-73. doi: 10.3171/ jns.1978.48.2.0264.

19. Takeshita M, Kagawa M, Izawa M, Takakura K. Current treatment strategies and factors influencing outcome in patients with bacterial brain abscess. Acta Neurochir (Wien). 1998;140(12):126370. doi: 10.1007/s007010050248.

20. Callovini GM, Bolognini A, Gammone V, Petrella G. First-line stereotactic treatment of thalamic abscesses: report of three cases and review of the literature. Cent Eur Neurosurg. 2009;70(3):143-8. doi: 10.1055/s-0029-1202360.

21. Quiñones-Hinojosa A, Ware ML, Sanai N, McDermott MW. Assessment of image guided accuracy in a skull model: comparison of frameless stereotaxy techniques vs. frame-based localization. J Neurooncol. 2006;76(1):65-70. doi: 10.1007/ s11060-005-2915-z.

22. Steinmeier R, Rachinger J, Kaus M, Ganslandt O, Huk W, Fahlbusch R. Factors influencing the application accuracy of neuronavigation systems. Stereotact Funct Neurosurg. 2000;75(4):188-202. doi: $10.1159 / 000048404$. 